\title{
Aircraft Spares Supply Chain Management for the Aviation Industry in Zambia Based on the Supply Chain Operations Reference (SCOR) Model
}

\author{
Danny Milambo', Jackson Phiri² \\ ${ }^{1}$ Graduate School of Business, University of Zambia, Lusaka, Zambia \\ ${ }^{2}$ Department of Computer Sciences, School of Natural Sciences, University of Zambia, Lusaka, Zambia \\ Email: dansmila@gmail.com, jackson.phiri@cs.unza.zm
}

How to cite this paper: Milambo, D. and Phiri, J. (2019) Aircraft Spares Supply Chain Management for the Aviation Industry in Zambia Based on the Supply Chain Operations Reference (SCOR) Model. Open Journal of Business and Management, 7, 1183-1195.

https://doi.org/10.4236/ojbm.2019.73083

Received: April 14, 2019

Accepted: July 2, 2019

Published: July 5, 2019

Copyright $\odot 2019$ by author(s) and Scientific Research Publishing Inc. This work is licensed under the Creative Commons Attribution International License (CC BY 4.0).

http://creativecommons.org/licenses/by/4.0/

\begin{abstract}
This research articulates the challenges faced in the Supply Chain Management (SCM) of aircraft spares in the Zambian Aviation Industry. The study was conducted in Lusaka, Zambia. It was discovered that some of the challenges faced in SCM were due to unreliable lead times, non-adherence to service level agreements between buyers and suppliers and the unavailability of local players in the industry among others. The sample size was purposively selected from the aviation industry in Zambia. Data were collected from one hundred respondents from public and private institutions in the Aviation sector which was later analysed using descriptive statistics. Based on the findings, it was concluded that the Supply Chain Operations Reference (SCOR) Model can be adopted to eliminate delays in procurement and delivery of spare parts and solve many other challenges found in the aviation industry in the Country. This can be ironed out using the model's five management practices of plan, source, make, deliver and return. The model structure also provides four major components (People, Practices, Processes and Performance) to assess the status of any given situation. These elements ensure a smooth supply chain for products as they incorporate demand management, inventory management, and freight management among others. The study recommended the need to employ Enterprise Resource Planning for supplier-vendor management and the need to adhere to service level agreements. Furthermore, it stressed on the need to use supply chain techniques in improving efficiency in the SCM function to reduce costs.
\end{abstract}

\section{Keywords}

Aircraft Spares, Enterprise Resource Planning, Aviation Industry, Supply 


\section{Introduction}

A key feature of present-day business is the idea that it is Supply Chains that compete, not companies and the success or failure of Supply Chains is ultimately determined in the marketplace by the end-consumer [1]. It has been argued that measuring Supply Chain performance can facilitate a greater understanding of the Supply Chain, and improve its overall performance [2]. Therefore, there is an emerging requirement to focus on the management of the Supply Chain or network in which company is a partner.

The arms-length types of relationships that have existed for years between buyers and suppliers with each party trying at every moment to guard their position in the business dealing without recourse to other stakeholders have affected the operational efficiency for decades [3]. Such type of supply chain management in the supply of aircraft spares has more often than usual resulting into delayed delivery of the spares in the Zambian Aviation Industry. The degree and cost to which the stained relationships have affected the purchase of aircraft spare parts in the Zambia have not been established and principles of good supplier relationship management have not been adhered to [4]. There is therefore, need to carry out a study to identify the challenges faced by the aviation industry in procurement of the aircraft spares and come up with possible solutions based on the Supply Chain Operations Reference Model.

The systematic study into the challenges and solutions of the supply chain management of aircraft spares in the Zambian aviation industry has never been explored. Research in this area will definitely benefit several stakeholders. To the Zambian Aviation Industry, it will act as an eye opener on the need to carry out an appraisal of the performance of their supply chains. The research findings will help managers in continuously seeking better ways of carrying out supply chain Management practices. To the airline industry at large, this work will definitely be a breakthrough as it addresses a dimension that will definitely result in cost savings. The Government in their bid to accelerate ICT development, which is an important enabler of innovation and economic development, through the launched Smart Zambia Project [5] as they drive towards the realization of their Vision 2030 will for sure benefit from this research work. By continuously evaluating the management of their supply chains, the Government will realize massive savings by employing good supply chain management practices.

\section{Literature Review}

Supply Chain Management as a set of approaches utilized to efficiently integrate suppliers, manufacturers, warehouses and stores, so that merchandise is produced and distributed in the right quantities, to the right locations at the right 
time in order to minimize system wide costs while satisfying service level requirements [6]. In managing the Supply Chain, an organisation needs to be strategic in order to obtain the benefits of the inter-connectivity [7]. Supply chain management model must meet the deadlines well from the beginning till the end. Organization's success is solely depending on how successful the delivery of the product is when it reaches the customer's hands. Right from the order processing to manufacturing, receiving, and quality checks and until delivery to the customer, SCM model must be fine-tuned appropriately [8]. A study in the supply chain management practices of the Boeing Commercial Airplane Company within the context of the global aerospace industry was conducted [9]. In this study, the results revealed that there were significant changes in supply chain management practices in the aerospace industry. These challenges included restructuring and closer integration of supplier networks to achieve efficiency gains; delegating greater design and production responsibility to major suppliers through strategic supplier partnerships along with having key suppliers evolve greater system and subsystem integration capabilities, emphasizing a lifecycle view supply chain design and management to reduce lifecycle cost of products and systems. Other challenges included building supply chain capabilities that supports maintenance and aftermarket logistics services as a major new strategic thrust to provide improved customer satisfaction and retain long-term customer loyalty.

Similarly, the United States Department of Energy in their study on supplier management improvement in aviation industry; a case of Beriev Aircraft Company in Russia studied and analyzed the domestic and international experience in supply chain management of the aviation industry to enhance the competitiveness of aircraft factory products [10]. The study revealed that the, strategic scenario of quality management improvement with the priority of supply chain management provided improved customer satisfaction.

Furthermore, another study on the Supply Chain Management challenges in the South African public sector' revealed that SCM had been fully employed across all spheres of government and customised policies developed as required by the SCM policy. Notwithstanding the employment of the concept, there are challenges that restrain full execution to achieve its potential. Barriers to public supply chain management strategy implementation still exist. These challenges stem from, among other things, non-compliance with SCM policies and regulations; fraud and corruption; lack of proper knowledge and skills [11]. The article concludes by suggesting a framework that could improve the public sector supply chain and ensure efficient and effective SCM implementation. Supply chain management model must meet the deadlines well from the beginning till the end. Organization's success is solely depending on how successful the delivery of the product is when it reaches the customer's hands. Right from the order processing to manufacturing, receiving, and quality checks and until delivery to the customer, SCM model must be fine-tuned appropriately [8].

The research organization RAND presented a series of what it termed "best 
practices in developing proactive supply strategies for the US Air Force low demand service parts" [4]. The research reviewed "Air Force purchases of low-demand spare parts [and analyzed] how much the Air Force spends on low-demand parts". The purpose of the research was to identify and synthesize best commercial purchasing and supply chain management practices used for developing supply strategies for such items and to recommend how the Air Force could improve its supply strategies for such items [4].

The above studies have made considerable contributions to understand some of the challenges faced in supply chain management of aviation spares within the aviation industry. However, no research has ever been conducted pertaining to the challenges in the current supply chain faced by the aviation industry in Zambia for the aircraft spare parts.

\section{Supply Chain Operation Reference Model}

The Process reference model integrates the well-known concepts of business process re-engineering, benchmarking and process measurement into a cross-functional framework as shown in Figure 1. The Model Contains standard description of management processes, a framework of relationships among the standard processes, standard metrics to measure process performance and management practices that produce best-in-class performance [12].

It brings about standard alignment to features and functionality in the supply chain. Once a Complex Management process is captured in Standard Process Reference Model Form, it can be implemented purposefully to achieve competitive advantage. It can be described unambiguously and communicated, measured, managed, controlled, tuned and re-tuned to a specific purpose [13].

The SCOR model has four main components that will be an area of focus for this research as shown in Figure 2.

\section{SCOR SCOPE}

\begin{tabular}{|c|c|c|c|}
\hline $\begin{array}{l}\text { Business Process } \\
\text { Re-Engineering }\end{array}$ & Benchmarking & $\begin{array}{l}\text { Best Practices } \\
\text { Analysis }\end{array}$ & $\begin{array}{l}\text { Process Reference } \\
\text { Framework }\end{array}$ \\
\hline $\begin{array}{l}\text { Capture the 'As-is' } \\
\text { business activity } \\
\text { structure and derive } \\
\text { the future 'To-be' state }\end{array}$ & $\begin{array}{l}\text { Quantify the } \\
\text { operational } \\
\text { performance of similar } \\
\text { companies and } \\
\text { establish internal } \\
\text { targets based on 'best } \\
\text { in class' results }\end{array}$ & $\begin{array}{l}\text { Characterize the } \\
\text { management practices } \\
\text { and software solutions } \\
\text { that result in superior } \\
\text { performance }\end{array}$ & $\begin{array}{l}\text { Capture the 'As-is' } \\
\text { business activity } \\
\text { structure and derive } \\
\text { the future 'To-be' state } \\
\text { Quantify the } \\
\text { operational } \\
\text { performance of similar } \\
\text { companies and } \\
\text { establish internal } \\
\text { targets based on 'best } \\
\text { in class' results } \\
\text { Characterize the } \\
\text { management practices } \\
\text { and software solutions } \\
\text { that result in superior } \\
\text { performance }\end{array}$ \\
\hline
\end{tabular}

Figure 1. Supply chain operation reference model (2002). 


\section{SCOR MODEL STRUCTURE}

\section{Four Major Components}

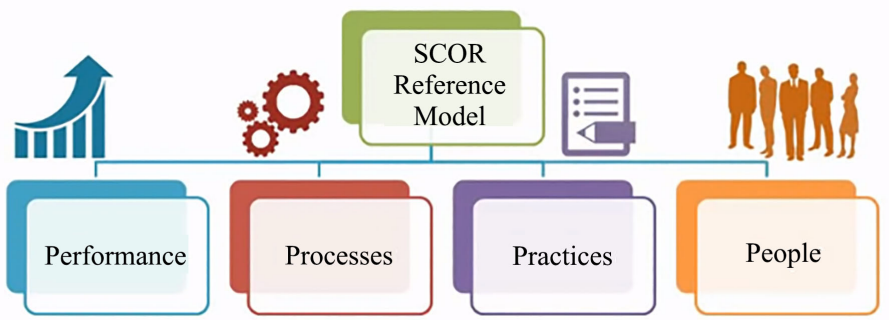

Figure 2. SCOR model structure (2002).

\section{Methodology}

[14] describes methodology as a set of tools and devices to be used at each time; why and how such tools and devises ought to be used. A research design is a course of action that guides a researcher in collecting, analyzing and interpreting data and observations to find answers to research questions [15].

This study used descriptive and quantitative survey design. According to [16] quantitative research often translates into the use of statistical analysis to make the connection between what is known and what can be learned through research, whereas qualitative is defined as a study which is conducted in a natural setting [15]. Qualitative research approach will provide an enquiry for understanding a social or human problem based on building a complex, holistic picture, formed with words, reporting detailed views of information and conducting it in a natural environment.

Population is the aggregate or totality of all objects, subjects or members that conform to a set of specifications [17]. Population can also be defined as the total number of units from which data can be collected, such as individuals, artifacts, events or organizations.

Therefore, the research design used was descriptive survey which gave a set view of the subject, population and market segment because descriptive research provides research questions, populations or methods of analysis even before the research is started [16]. This research targeted employees in the Zambian aviation sector in various departments including both public and private institutions involved in the aviation industry in the country.

The study included the staff from various departments in the aviation industry from Finance, Supply Chain Management, Aeronautical Engineering and Stores Management.

The researcher adopted a sample size using purposive sampling method and applied the Yamane formula:

$$
n=\underline{N}
$$

$$
\left[1+N\left(\mathrm{e}^{2}\right)\right]
$$

where 
$n$ is the sample size;

$N$ is the representation of the population size and

$e$ the level of precision ( $\pm 5 \%)$ giving confidence level of $95 \%$. Consequently, the sample size was determined as:

$$
n=N /\left[1+N\left(\mathrm{e}^{2}\right)=133 / 1+133\left(0.05^{2}\right)\right]=100
$$

Therefore, One Hundred (100) respondents were an adequate representation of the population to depict the staff from various departments of interest in the aviation industry. There searcher used a questionnaire to collect primary data while secondary data (data which is collected by someone who is someone other than the user. This includes censuses, information collected by government departments, organizational records and data that was originally collected for other research purposes) was collected from both the published and unpublished material such as journals, compiled reports; and articles in print and electronic media. The MS excel and SPSS were used to analyze the data using descriptive statistics as a statistical method in the research.

This research adapted the SCOR Model which was used in collaboration with the CIPS Purchasing and Supply Management Model. The model describes the business processes required to satisfy a customer's demands. It also helps to explain the processes along the entire supply chain and provides a basis for how to improve those processes [12].

The model integrates business concepts of process re-engineering, benchmarking, and measurement into its framework. It has been described as the "most promising model for supply chain strategic decision making. This framework focuses on five areas of the supply chain: plan, source, make, deliver, and return. These areas repeat again and again along the supply chain. The supply chain council says this process spans from "the supplier's supplier to the customer's customer".

Figure 3 shows the model which was adapted to look at various factors to address the challenges of the supply chain of aircraft spares for the Zambian aviation industry. Key things considered were the barriers to the supply chain system in the Zambian aviation industry by benchmarking best practices in the United Kingdom, United States of America and the Republic of South Africa.

\section{Results}

The results of this study were obtained in the context of the objectives of the study and the challenges faced by the aviation industry in procurement of the aircraft spares in Zambia based on the Supply Chain Operations Reference (SCOR) Model. In Figure 4, it is observable that there is a strong positive statistically significant relationship between variables. This is evident from the pearson correlation or pearson's $r$ that is close to the value of 1 .

\subsection{Basic Statistical Analysis}

The study findings showed that majority of the respondents had at least attained 
tertiary education as shown in Figure 5. The participants understood the importance of having a well functional SCM system for supply of spare parts for the aviation industry. The people section of the SCOR Model provides a standard for describing skills required to perform tasks and manage processes [12]. About $10 \%$ of respondents had a master's degree, while $30 \%$ held at least an undergraduate degree. About $55 \%$ had either a diploma or certificate. Having people either in a higher qualification or striving for one can impart positively on the efficiency and smooth operation and/or implementation of company strategies, among them modern SCM systems.

Further, the study showed that $75 \%$ of the respondents had been in the aviation industry for over 10 years. This shows a great skills pool to have a well-equipped SCM team for the aviation industry spare parts management. From the outcome only $25 \%$ had less than 10 years of experience in the aviation industry (Figure 6).

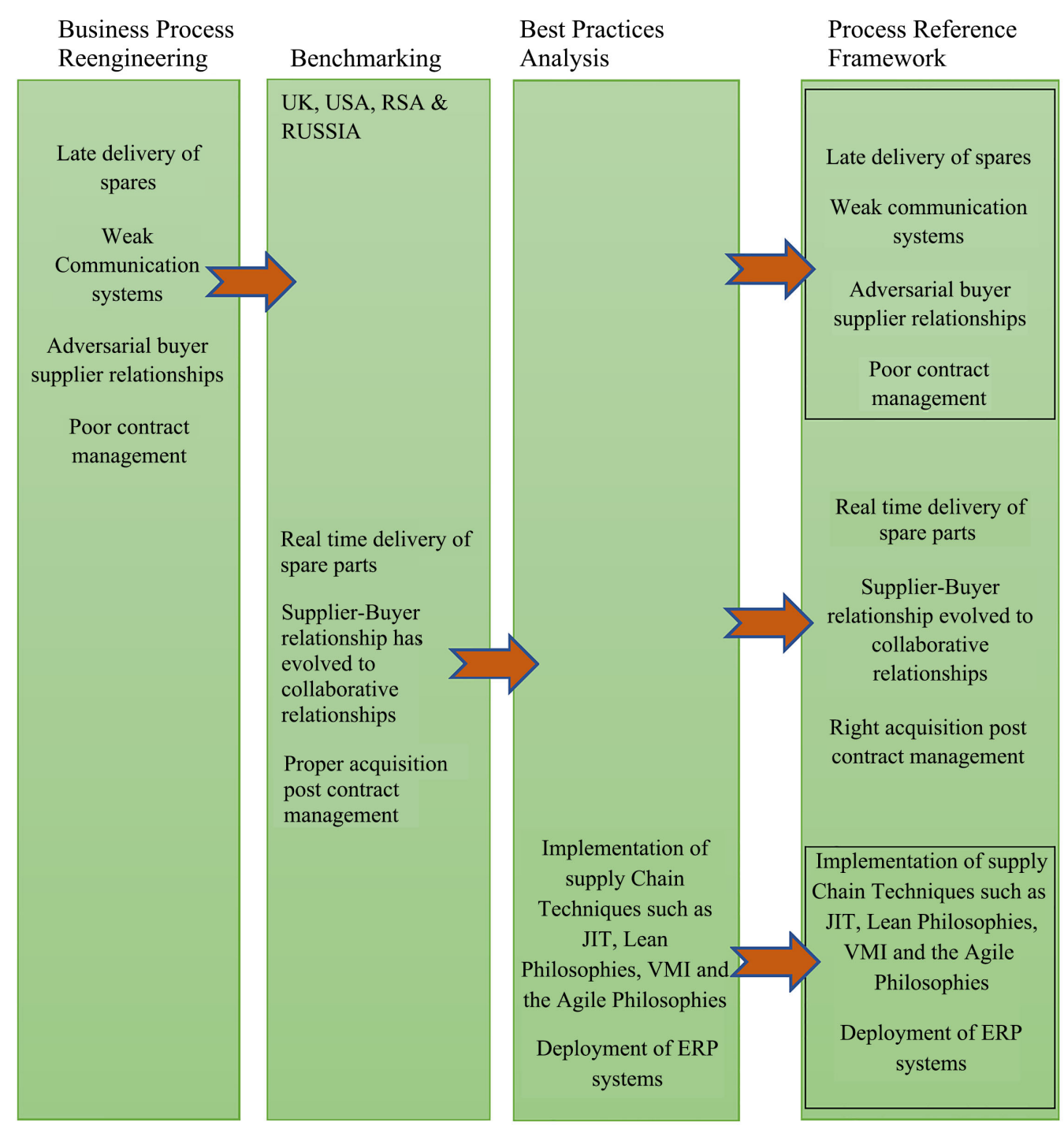

Figure 3. Research model developed for this study. 


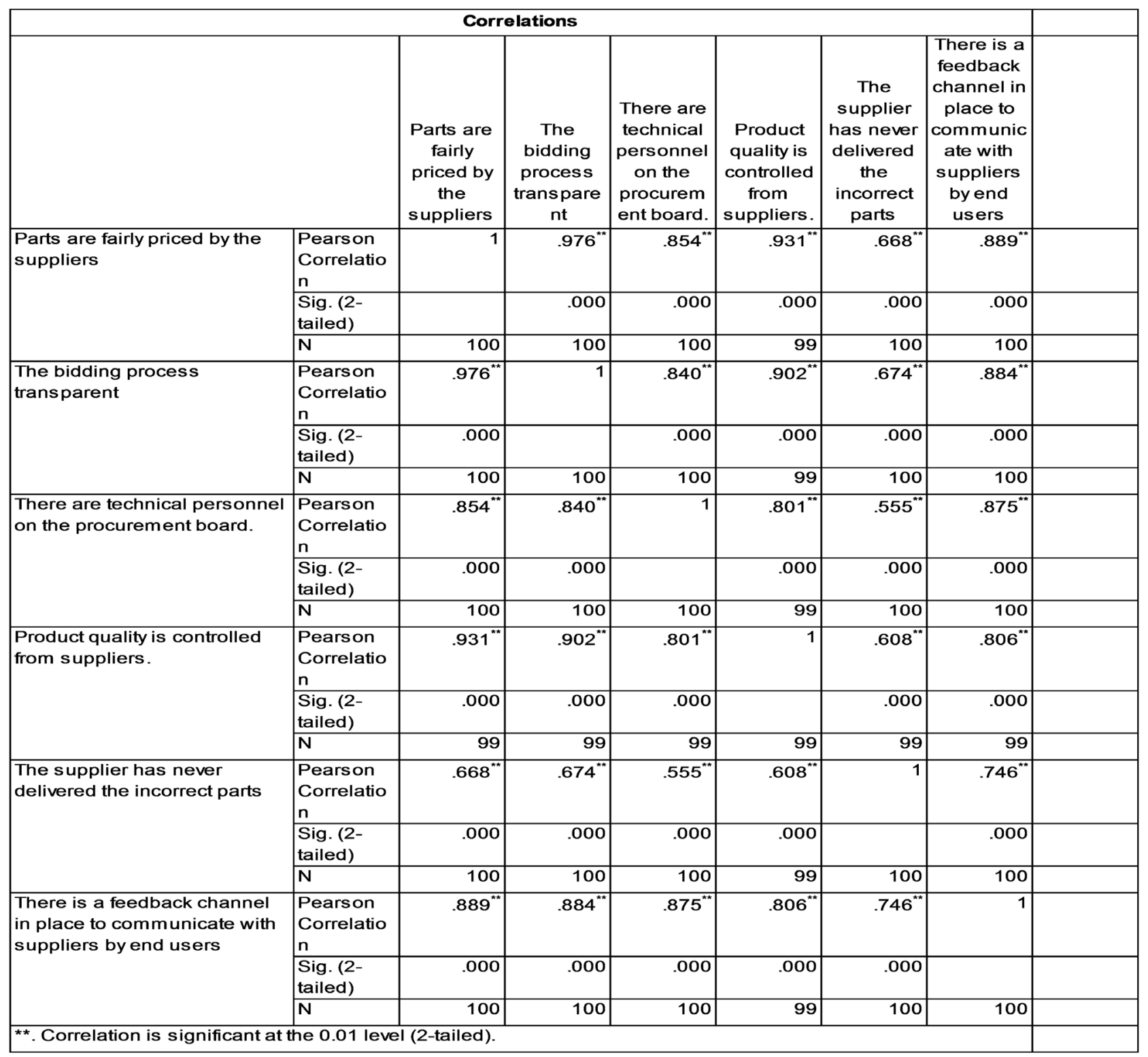

Figure 4. Correlation coefficient analysis.

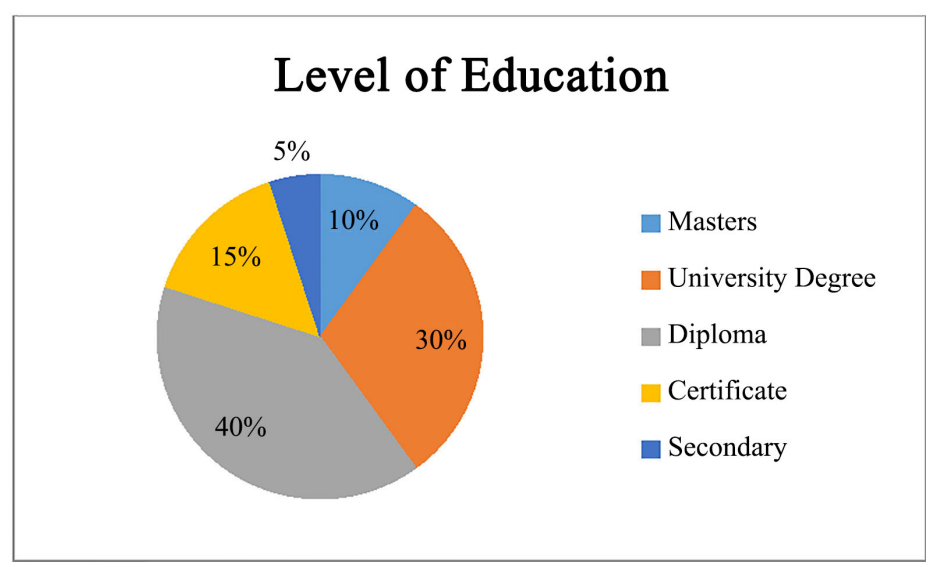

Figure 5. Respondents level of education. 


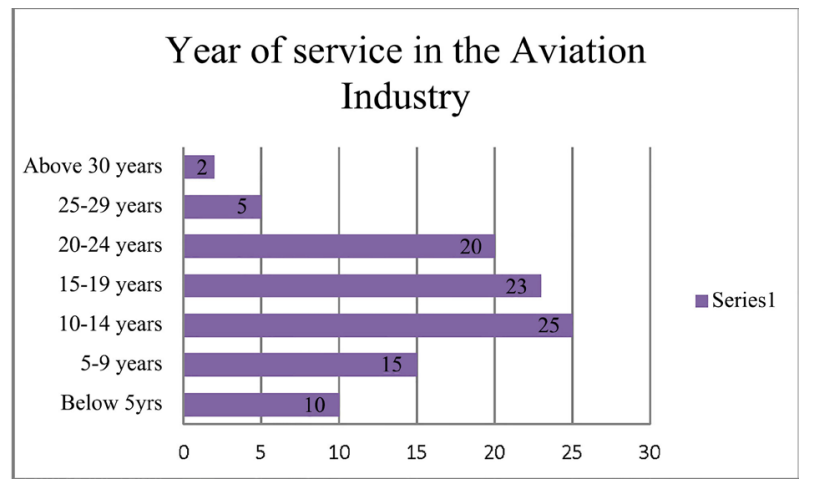

Figure 6. Years of service in the aviation in industry.

\subsection{Statistical Analysis Based on the Supply Chain Operation Reference Model}

\subsubsection{Inefficient Procurement Systems}

The Supply Chain Operations Reference Model (SCOR) describes the business processes required to satisfy a customer's demands [12]. The customers' demands are met by satisfying the four main components of the model structure. In this segment of the study, practices and processes were examined. The respondents in the study were asked if they considered the procurement system to be efficient and if they would recommend the use of e-auctioning platforms. The findings revealed that $60 \%$ of the respondents strongly agreed that the procurement systems were not efficient as they were paper based and manual in nature. The study proposed the introduction of e-procurement systems and employment of e-auctions to allow for more competition in the bidding processes as illustrated by $80 \%$ of the respondents being in agreement as shown in Figure 7 . The two parameters indicated that the procurement systems in the aviation industry were inefficient.

\subsubsection{Unreliable Lead Times}

The performance of the supply chain is considered perfect if the original commitment made to a customer is met through the supply chain [12]. Figure 8 shows responses of how the supply chain pertaining to delivery of spares performs. The study findings revealed that there is less use of integrated procurement systems which has led to delays in delivery of spares as can be seen from the $89 \%$ respondents affirming delays in the procurement process. Further, non-application of supply chain techniques like VMI has equally contributed to unreliable lead times as confirmed by almost $90 \%$ respondents.

\subsubsection{Poor Contract Management}

The study revealed post contract challenges pertaining to service level agreements and appropriate supplier/buyer relations. $90 \%$ of respondents indicated that suppliers of aviation spares consumers had outstanding debt to suppliers. Issues of late payment to suppliers and debt management were revealed as evidenced by $78 \%$ respondents who said suppliers are sometimes not paid on time (Figure 9). 


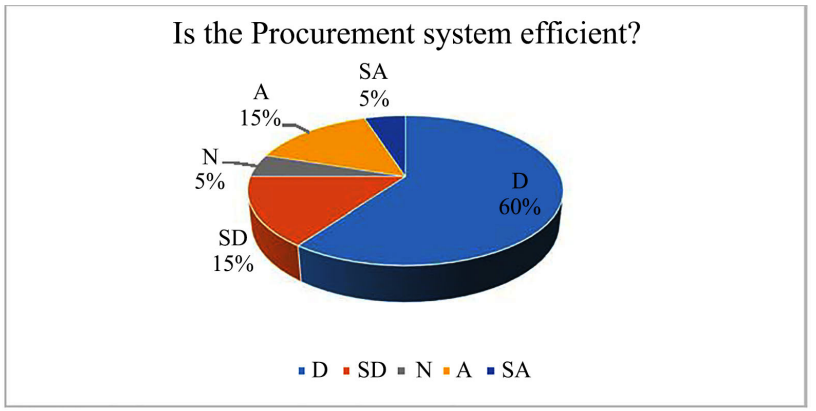

(a)

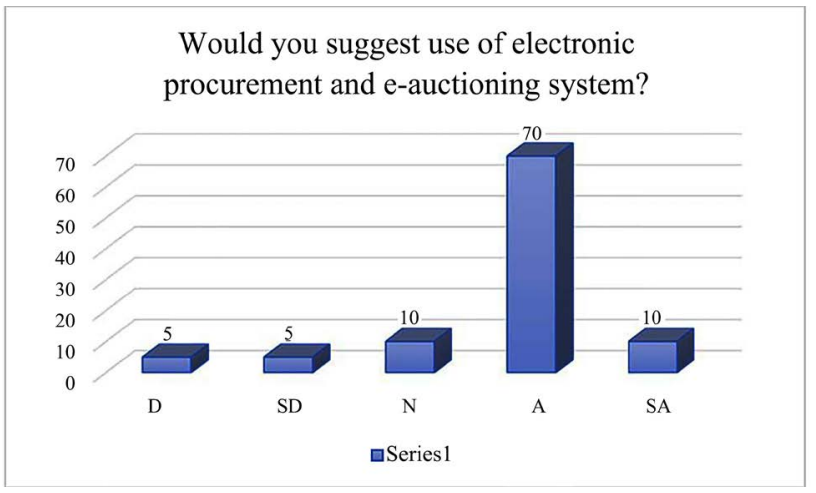

(b)

Figure 7. Inefficient procurement systems.

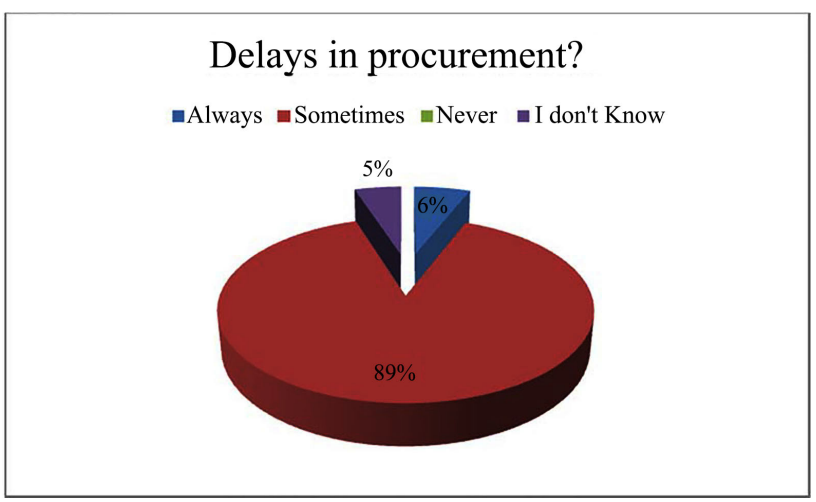

(a)

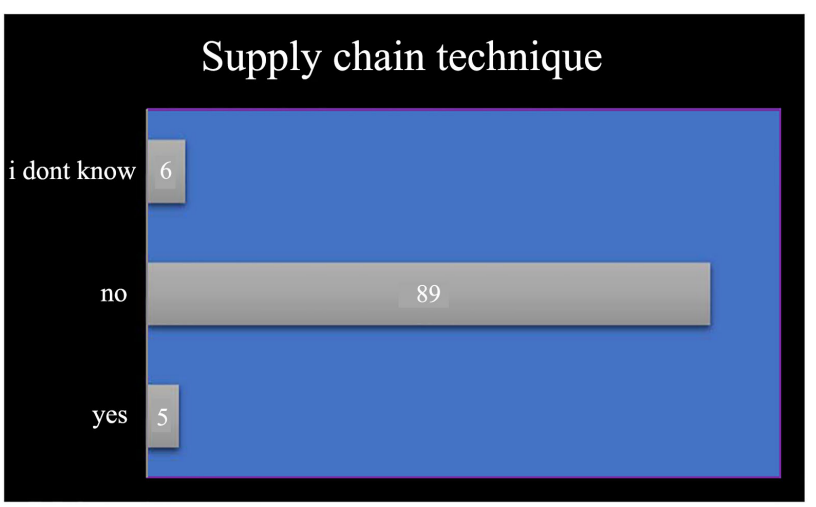

(b)

Figure 8. Unreliable lead times. 


\section{Outstanding debt to suppliers}

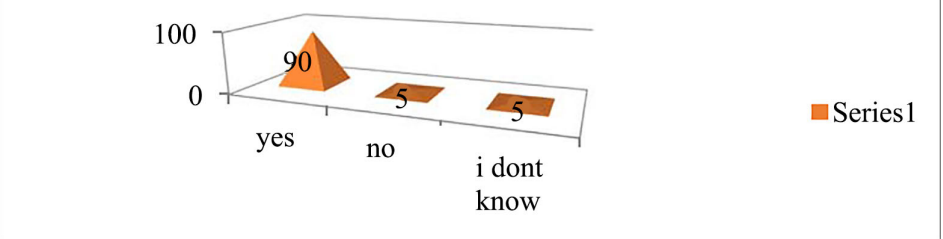

(a)

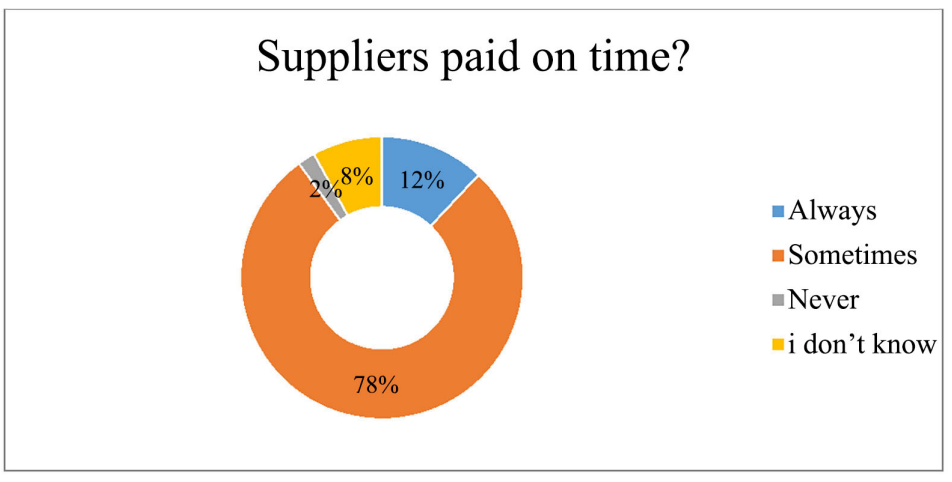

(b)

Figure 9. Poor Contract management.

\section{Limitations}

Like any research, this study also encountered some limitations. Limitations of the study refer to those factors of research design or methodology that can influence the interpretation or application of the findings of the study [18]. Data quality constraints associated with quantitative research are highlighted by [19] as prone to misinterpretation, difficulties in getting in-depth information, tend to be artificial and requires high levels of literacy by respondents.

The method of sampling used non probability sampling (purposive sampling) which is prone to the following limitations; sample may not be a representation of the population, samples are likely to be prone to errors thus limiting the generalizability of the findings. The research is purely descriptive there is therefore need to scientifically test the variables to determine the relationship of the independent and dependent variables.

\section{Conclusion}

This thesis concludes that the SCOR model can be a great tool in improving the SCM of aviation spare parts in Zambia. Evaluation of suppliers is much easier if there's in existence an integrated system as it can readily give supplier information at the click of a button and help address late payment to suppliers and management of contracts. The application of supply chain techniques in SCM would eliminate waste and reduce costs. The SCOR model's five management practices of plan, source, make, deliver and return will ensure a smooth supply chain for spare parts as they help in improving the lead times for parts delivery. 


\section{Recommendations}

From the results of the study, as well as the research gaps noted in the literature review, the following recommendations are made:

- There is need for an integrated supplier-vendor management system to enable the ease of procurement, storage and distribution of spare parts for the aviation industry. This system improves easy inventory control, demand management, saves time and resources and also improves efficiency of the Supply Chain Management opposed to paper-based manual systems.

- There is need to promote use of the SCOR management processes; plan, source, make, deliver and return processes in the SCM as it will enable the right forecasting, sourcing and timely delivery of goods.

- There is need to review contracts with suppliers to draw a line of best fit that will give a win-win situation for both the suppliers and the buyers. Debt, payment plans, quality and delivery times have to be reviewed so as to create a good working relationship with suppliers. There is also need for adherence to the service level agreements by either party.

- The organisations in the aviation industry need to utilize supply chain techniques such as Vendor Managed Inventory whereby investors setup local warehouses and/or manufacturing sites in Zambia. This will improve the lead time for spares delivery and impact positively on the performance of the aviation sector. This will also enhance timely access to spares and reduction on costs.

\section{Acknowledgements}

The authors wish to acknowledge the valuable support of everyone who helped in the actual administration of the questionnaire and all the other participants of the study.

\section{Conflicts of Interest}

The authors declare no conflicts of interest regarding the publication of this paper.

\section{References}

[1] Gill, P. (2013) Relationship between Key Performance Indicators in Supply Chain Management. International Journal of Industrial Engineering and Technology, 5, 7-16.

[2] Kurien, G.P. and Qureshi, M.N. (2011) Study of Performance Measurement Practices in Supply Chain Management. International Journal of Business, Management and Social Sciences, 2, 19-34.

[3] Addae, C. (2015) Supplier Relationship Management Practices of Ministries, Department and Agencies (MDA's) in Ghana (Supplier Perspective): A Case of Ghana Highway Authority.

[4] Chenoweth, M.E., Arkes, J. and Moore, NY. (2012) Best Practices in Developing Proactive Supply Strategies for Air Force Low-Demand Service Parts. RAND Cor- 
poration, Santa Anna, CA.

[5] Lusaka: S.Z.I. (2018) A Smart and Value Centered Public Service. SMART Zambia Institute Institute.

[6] Lysons, K. (2006) Purchasing and Supply Chain Management. FT Prentice Hall, London.

[7] Scholes, J., et al. (2012) Exploring Strategy. FT Prentice Hall, London.

[8] Zhang, C. (2012) The Study on the Enterprises' E-Procurement in China. 2012 3rd International Conference on System Science, Engineering Design and Manufacturing Informatization, Chengdu, 20-21 October 2012, 233-236. https://doi.org/10.1109/ICSSEM.2012.6340716

[9] Cizmec, D. (2005) An Examination of Boeing's Supply Chain Management Practices within the Context of the Global Aerospace Industry. Master's Thesis, Massachusetts Institute of Technology, Cambridge, MA.

[10] Doe, D.M. (2002) E-Procurement and the US Military.

[11] Mafini, C. (2016) Barriers to Public Supply Chain Management Strategy Implementation: An Exploratory Diagnosis. Problems and Perspectives in Management. Problems and Perspectives in Management, 14, 256-265.

[12] Supply Chain Council (SCC) (2002) Supply Chain Operations Reference Model.

[13] Smith, A.G. (2001) Applying Evaluation Criteria to New Zealand Government Websites. International Journal of Information Management, 21, 137-149.

[14] Creswell, J.W. (2013) Research Design: Qualitative, Quantitative, and Mixed Methods Approaches. SAGE Publications, Thousand Oaks, CA.

[15] Trochim, W.M.K. (2006) The Qualitative Debate. Research Methods Knowledge Base.

[16] Polit D.F. and Hungler, B.P. (2004) Nursing Research: Principles and Methods. 6th Edition, Lippincott Williams \& Wilkins, Philadelphia, PA.

[17] Angelin, N. (2016) Is Vendor Managed Inventory Right for Your Aircraft Expendable Needs?

[18] Yin, R. (2009) Case Study Research: Design and Methods. Sage Publications, Thousand Oaks, CA.

[19] Saunders, M.L. (2012) Research Methods for Business Students. 6th Edition, Pearson, Harlow. 